\title{
An Enhanced LEACH in Wireless Sensor Network
}

\author{
Navjot Kaur, Manish Mahajan, Rajeev Sharma
}

\begin{abstract}
Wireless sensor networks (WSNs) consist of self-governing sensors that sense as well as monitor the area in which these nodes are deployed and distribute this information in a distributed manner. Presently, the WSN with long life and minimum energy consumption are in demand. To overcome this problem, Low Energy Adaptive Clustering Hierarchy (LEACH) is presented with the addition of Cuckoo Search (CS) and Support Vector Machine (SVM) concept. The problem of LEACH protocol like which node is considered as Cluster Head (CH) is overcome by CS. On the basis of healthy function, the nodes property such as energy consumed by each node is categorized. Those nodes that have higher energy compared to the defined function are put in one category and remaining in another category. These two categories of nodes are provided as an input to SVM and train the system. Therefore, the best node having the highest energy is considered as $\mathrm{CH}$ and hence enhanced the lifetime by saving the energy upto $21.86 \%$.
\end{abstract}

\section{Index Terms: WSN, LEACH, CS, SVM, CH.}

\section{INTRODUCTION}

WSNs are made up of many sensors nodes that are powered with a small battery. The geometric configuration of this network consists of a number of sensor nodes with different processing elements and power resources. The performance of these networks is affected by environment conditions [1]. In the modern era, WSN is considered as an important technique, which is mostly used by doctors, military and for the detection of environmental conditions. The communicating elements used in WSN have the benefits as the size as well as the cost is small. These devices are powered by a small battery [2].After the implementation of these devices in the field, the battery cannot be replaced. Therefore, the long life of these networks is limited by the limited energy. To save energy becomes a current topic of research. The general diagram of WSN is shown in fig. 1[3].

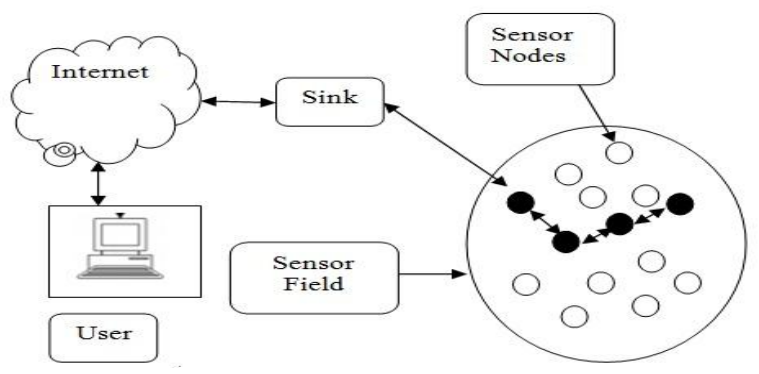

Revised Manuscript Received on June 15, 2019.

Navjot Kaur, CSE, Chandigarh Engineering College, Mohali, Punjab. Dr. Manish Mahajan, CSE, Chandigarh Engineering College, Mohali, Punjab.

Rajeev Sharma, CSE, Chandigarh Engineering College, Mohali, Punjab.
The nodes deployed in the network are indicated by a circle, which is known as the sensor field. Whenever the nodes want to transmit data, the node forms a route using some routing protocol as indicated by a dark circle and the direction of transmission is represented by an arrow [4].

The problem of energy consumption and hence to increase the lifetime of the network, the available communication protocols need to be modified. The available routing protocols are categorized into two types named as plane routing and layered routing. Since the plane routing protocols suffer from the disadvantages that these cannot be applied to the larger area as this required larger space and hence consume more energy [5]. The layered routing protocols might be used in large area networks; an example of these routing protocols is LEACH.It works on the principle of cluttering so that the data can be transmitted to the cluster head near to it without forwarding messages to the nearby node and hence save energy [6].

Also, to enhance or balance the energy, LEACH routing protocol in combination with CS and SVM as a classification algorithm has been used.

Table1: Issue in WSN

\begin{tabular}{|c|c|}
\hline Issues & Description \\
\hline $\begin{array}{c}\text { Range \& } \\
\text { Connection }\end{array}$ & $\begin{array}{c}\text { Sensor nodes used smaller } \\
\text { bandwidth with less low power }\end{array}$ \\
\hline $\begin{array}{c}\text { Location \& } \\
\text { synchronization }\end{array}$ & $\begin{array}{c}\text { The position of sensor nodes is } \\
\text { very important as the user can } \\
\text { know about the state of nodes } \\
\text { such as active or sleep node }\end{array}$ \\
\hline $\begin{array}{c}\text { Power } \\
\text { Management }\end{array}$ & $\begin{array}{c}\text { As very necessary as it decides } \\
\text { the lifetime of the network } \\
\text { the event occurred in the network } \\
\text { urgently, therefore the network } \\
\text { must have a process that event } \\
\text { with less delay }\end{array}$ \\
\hline
\end{tabular}

\section{Routing IN WSN}

Routing is the process to search route between the source and the destination node. Routing also helps for the transmission of data from one node to another node [8]. In WSN, routing is mainly categorized into three types as shown in the figure below. 


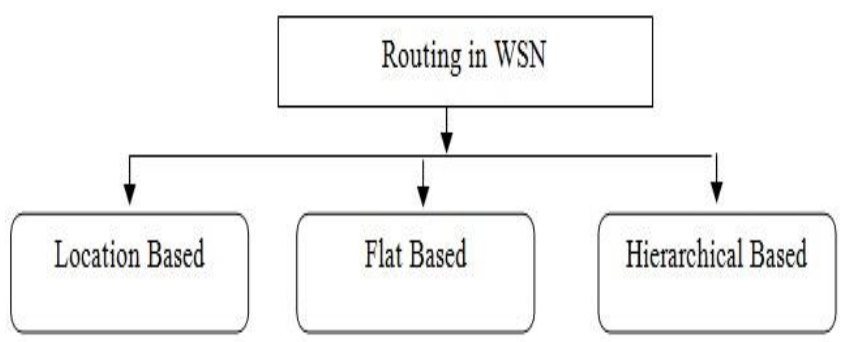

\section{A. Location Based}

In location-based routing protocol, it is assumed that all nodes know along with source node knows its location as well as the neighbours' location. In this scheme, the data is forwarded as per the greedy forwarding approach. In this approach, the node forward data all the time to the node whose Euclidean distance is smaller [9]. An example of location-based routing is shown in figure 3.

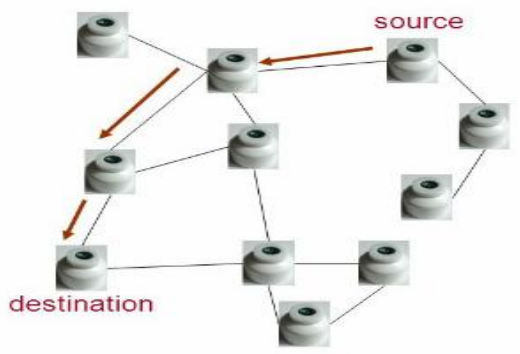

Fig 3. Location Based Routing

\section{B. Flat Routing}

It is a network communication protocol which is implemented by a router, in which all routers are interconnected to each other. Also, the information is provided by these routers without following any organization structure [10].

\section{Hierarchical Routing Protocol}

Hierarchal routing protocol effectively utilizes data aggregation to reduce the amount of network data streams. With hierarchical multi-hop routing algorithms, the sensor node accepts different roles that can be changed over time. It is also known as cluster-based routing that can be utilized to reduce the energy consumed by sensor nodes. During this process, the nodes having higher energy are used for the data transmission whereas the nodes with low energy are used to sense the data only. The LEACH is the example of Hierarchical routing algorithm [11].

\section{LEACH PRotocol}

It is the first energy efficient protocol that is used to create a route on the basis of energy consumed by the node. In $\mathrm{LEACH}$, the network is divided into clusters as shown in fig. 2.

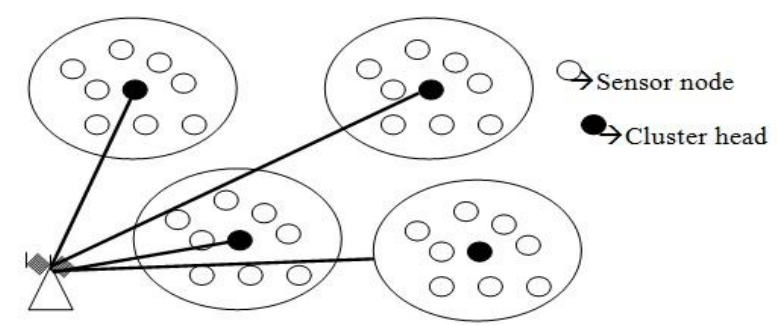

Fig 3. Leach Architecture

The entire network comprises of four different clusters each includes sensor nodes with cluster head $(\mathrm{CH}) . \mathrm{CH}$ is the heart of the route formation, through which the data transmission is possible, the remaining nodes are known as cluster members. The route is formed through two phases: Set up phase and Steady-state phase [7].

\section{A. Setup phase}

In this phase, the selection of $\mathrm{CH}$ is performed. Initially, the entire network nodes choose a number between $0 \& 1$. The selected number is then compared with the formula written below.

$$
\begin{gathered}
\mathrm{T}(\mathrm{m})=\frac{\text { Prob }}{\left.1-\text { prob(qmodprob }^{-1}\right)} \forall \mathrm{m} \in \mathrm{Grp} \\
\mathrm{T}(\mathrm{m})=0 \forall \mathrm{m} \nexists \mathrm{Grp}
\end{gathered}
$$

Here, $\mathrm{m}$ is a random number lies between 0 and 1

Prob- is the probability of cluster head

Grp is the group of nodes that were not clustered heads in the previous rounds

$\mathrm{T}(\mathrm{m})$ - is the threshold value

The node whose value is less than the threshold number is defined as $\mathrm{CH}$ for that particular round [8].

\section{B. Steady State Phase}

In this phase, the data is transmitted to the base station with the minimization of overload. Also, the time required in the set-up phase is more than the time required in the steady-state phase [9].

Some of the LEACH protocols based on enhancements are as given below:

\begin{tabular}{|c|c|}
\hline $\begin{array}{l}\text { Protocol } \\
\text { Name }\end{array}$ & Description \\
\hline$F-L E A C H$ & $\begin{array}{l}\text { A protocol forsecuring node to node } \\
\text { communication in LEACH-basednetwork. It } \\
\text { used random key pre-distribution scheme } \\
\text { withsymmetric key cryptography to enhance } \\
\text { security inLEACH. FLEACH provides } \\
\text { authenticity, integrity,confidentiality and } \\
\text { freshness to node-to-nodecommunication. } \\
\text { But it is vulnerable to node capturingattack } \\
\text { [4]. }\end{array}$ \\
\hline SLEACH & $\begin{array}{l}\text { This is the first modified secure version } \\
\text { of LEACHcalled SLEACH, which } \\
\text { investigated the problem of addingsecurity to } \\
\text { cluster-based communication protocol } \\
\text { forhomogeneous wireless sensor networks } \\
\text { consisting of sensornodes with severely } \\
\text { limited resources. }\end{array}$ \\
\hline SHEER & $\begin{array}{l}\text { a secure hierarchical energyefficient } \\
\text { routing protocol (SHEER) which provides } \\
\text { securecommunication at the network layer. It } \\
\text { uses theprobabilistic broadcast mechanism } \\
\text { and three-levelhierarchical clustering } \\
\text { architecture to improve the networkenergy } \\
\text { performance and increase its lifetime }\end{array}$ \\
\hline \multicolumn{2}{|c|}{$\begin{array}{l}\text { Published By: } \\
\text { Blue Eyes Intelligence Engineering } \\
\& \text { Sciences Publication }\end{array}$} \\
\hline
\end{tabular}

Table2: LEACH Protocols 


\begin{tabular}{|c|c|}
\hline Sec-LEACH & $\begin{array}{l}\text { Sec-LEACH provides an efficient } \\
\text { solution for securingcommunications in } \\
\text { LEACH. It used random-keypredistribution } \\
\text { and TESLA for secure hierarchical } \\
\text { WSNwith dynamic cluster formation. } \\
\text { Sec-LEACH appliedrandom key distribution } \\
\text { to LEACH, and introducedsymmetric key } \\
\text { and one way hash chain to } \\
\text { provideconfidentiality and freshness. } \\
\text { Sec-LEACH providesauthenticity, integrity, } \\
\text { confidentiality and freshness to } \\
\text { communications. }\end{array}$ \\
\hline SS-LEACH & $\begin{array}{l}\text { a secure hierarchical protocolcalled } \\
\text { SS-LEACH, which is the secure version of } \\
\text { LEACH.SS- LEACH improves the method } \\
\text { of electing cluster headsand forms dynamic } \\
\text { stochastic multi-paths cluster headschains to } \\
\text { communicate to the base station, In this way } \\
\text { itimprove the energy-efficiency and hence } \\
\text { prolong thelifetime of the network. }\end{array}$ \\
\hline RLEACH & $\begin{array}{l}\text { Secure solution for LEACH has been } \\
\text { introduced calledRLEACH [4] in which } \\
\text { cluster are formed dynamically } \\
\text { andperiodically. In RLEACH the orphan } \\
\text { node problem israised due to random } \\
\text { pair-wise key scheme so they haveused } \\
\text { improved random pair-wise key scheme to } \\
\text { overcome.RLEACH has been used the one } \\
\text { way hash chain,symmetric and asymmetric } \\
\text { cryptography to providesecurity in the } \\
\text { LEACH Hierarchical routing protocol. }\end{array}$ \\
\hline
\end{tabular}

\section{RELATED WORK}

A number of researchers have used LEACH protocol to enhance the performance of the network. A few of work presented by different researchers in this area has been discussed in this section.[10][11]

Heinzelman et al. $(10,2002)$ have used LEACH protocol for the data transmission. The authors have considered the amount of remaining energy while selecting the $\mathrm{CH}$. There is an reduction of about $40 \%$ in the energy with the increase in the speed of data transmission has been obtained.Muruganathan, et al $(11,2005)$ a centralized approach has been used, which distributed the energy among the entire nodes deployed in the network. In this paper, the authors have used the base stations that are powered with high energy in order to accomplish the higher energy task.Ghasemzadeh $(12,2014)$ have used Bayesian Network model to select the $\mathrm{CH}$. This model has worked on the basis of three different parameters such as the distance to base station, residual energy as well as the density. The probability of each $\mathrm{CH}$ has been calculated. The dynamic zoning method along with a greedy mechanism has been used to distribute $\mathrm{CH}$ uniformly, which results in increase in the lifetime of the network.[12]Wang et al. $(13,2012)$ the concept of relaying node has been considered to enhance the selection of $\mathrm{CH}$.Also have considered the residual energy of the node during the selection of the cluster head, the possibility of selecting the low energy node as the cluster head is reduced. Based on the remaining energy and the distance to the base station, the relay node is selected from the $\mathrm{CH}$ to become a relay node between the base station and other CH's. The simulation results have shown that the LEACH-R protocol balancedthe network energy consumption and increase the network life cycle with high efficiency.[13][14]

\begin{tabular}{|c|c|c|c|}
\hline $\begin{array}{c}\begin{array}{c}\text { Referen } \\
\text { ces }\end{array} \\
\end{array}$ & \begin{tabular}{|l|l|}
$\begin{array}{l}\text { Proposed } \\
\text { work }\end{array}$ \\
\end{tabular} & $\begin{array}{l}\text { Technique } \\
\text { used }\end{array}$ & Findings \\
\hline $\begin{array}{r}\text { Xu et al. } \\
(14,2012)\end{array}$ & $\begin{array}{l}\text { The remaining } \\
\text { power of the } \\
\text { sensor nodes has } \\
\text { been utilized for } \\
\text { the network load } \\
\text { balancing. }\end{array}$ & E-LEACH & $\begin{array}{l}\text { The network } \\
\text { lifetime up to } 40 \\
\% \text { has been } \\
\text { increased. }\end{array}$ \\
\hline \begin{tabular}{l}
\multicolumn{1}{c}{ Manjes } \\
hwar, A., \& \\
Agrawal, \\
D. P. (15, \\
2001)
\end{tabular} & $\begin{array}{l}\text { The network } \\
\text { has been divided } \\
\text { as per the nodes' } \\
\text { functioning such } \\
\text { as active and } \\
\text { passive. The } \\
\text { performance of } \\
\text { TEEN algorithm } \\
\text { has been } \\
\text { measured in the } \\
\text { re-active } \\
\text { network. }\end{array}$ & \begin{tabular}{l}
\multicolumn{1}{c}{ Threshold } \\
sensitive \\
Energy \\
Efficient \\
sensor \\
Network \\
protocol \\
(TEEN)
\end{tabular} & 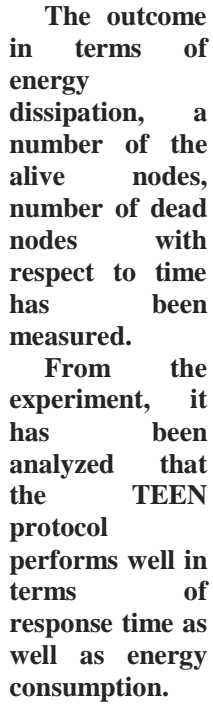 \\
\hline $\begin{array}{l}r \text { Wang et } \\
\text { al. } \quad(16, \\
2018)\end{array}$ & $\begin{array}{l}\text { The main aim } \\
\text { of this paper is to } \\
\text { divide the entire } \\
\text { network into a } \\
\text { number of the } \\
\text { grid. } \\
\text { The coverage } \\
\text { area of each grid } \\
\text { is decided as per } \\
\text { the energy } \\
\text { consumed by } \\
\text { each grid. }\end{array}$ & $\begin{array}{c}\text { Particle } \\
\text { Swarm } \\
\text { Optimization } \\
\text { (PSO) }\end{array}$ & $\begin{array}{c}\text { The average } \\
\text { energy } \\
\text { consumed by the } \\
\text { nodes of about } 1 \\
\mathrm{~J} \text { has been } \\
\text { achieved }\end{array}$ \\
\hline $\begin{array}{l}\text { Sarkar, } \\
\text { A., } \\
\text { \&Murugan } \\
\text {, T. S. (17, } \\
\text { 2019) }\end{array}$ & $\begin{array}{l}\text { In this paper, } \\
\text { the CH selection } \\
\text { approach is used, } \\
\text { which helps in the } \\
\text { reduction of } \\
\text { energy } \\
\text { utilization. }\end{array}$ & $\begin{array}{c}\text { CH } \\
\text { selection with } \\
\text { Firefly } \\
\text { algorithm }\end{array}$ & $\begin{array}{l}\text { Using the } \\
\text { firefly algorithm } \\
\text { the distance } \\
\text { among the nodes } \\
\text { becomes small } \\
\text { and hence the } \\
\text { possibility of the } \\
\text { number of alive } \\
\text { nodes has } \\
\text { increased. }\end{array}$ \\
\hline $\begin{array}{l}\text { Karabo } \\
\text { ga, D., } \\
\text { Okdem, } \\
\text { S., } \\
\text { \&Ozturk, } \\
\text { C. (18, } \\
\text { 2012) }\end{array}$ & \begin{tabular}{l}
\multicolumn{1}{c}{ In this } \\
research, the \\
information is \\
collected from the \\
network in a \\
particular time \\
slot.
\end{tabular} & $\begin{array}{c}\text { LEACH } \\
\text { with ABC }\end{array}$ & $\begin{array}{l}\text { The energy } \\
\text { with } \mathrm{ABC} \text { and } \\
\text { LEACH up to } \\
0.6 \mathrm{~J} \text { has been } \\
\text { normalized. }\end{array}$ \\
\hline
\end{tabular}




\begin{tabular}{|c|c|c|c|}
\hline $\begin{array}{l}\text { Kovend } \\
\text { an et al. } \\
(19,2018)\end{array}$ & $\begin{array}{l}\text { ANN is used to } \\
\text { select the route } \\
\text { which consumes } \\
\text { minimum energy }\end{array}$ & $\begin{array}{r}\text { LEACH } \\
\text { with ANN }\end{array}$ & $\begin{array}{l}\text { The } \\
\text { performance in } \\
\text { terms of } \\
\text { throughput, } \\
\text { energy and } \\
\text { Packet delivery } \\
\text { ratio has been } \\
\text { determined. } \\
\text { The Average } \\
\text { of energy, } \\
\text { throughput and } \\
\text { PDR are about } \\
\text { 300mJ, 50 and } \\
0.55 \text { has been } \\
\text { achieved. }\end{array}$ \\
\hline $\begin{array}{l}\quad \text { Moham } \\
\text { med } \\
\text { Omari ; So } \\
\text { umiaLarou } \\
\text { i(2015) }\end{array}$ & $\begin{array}{l}\text { Different } \\
\text { clustering } \\
\text { protocols have } \\
\text { been } \\
\text { implemented by } \\
\text { them. }\end{array}$ & $\begin{array}{l}\text { LEACH, } \\
\text { LEACH-C, } \\
\text { LEACH-1R, } \\
\text { and HEED }\end{array}$ & $\begin{array}{l}\text { The } \\
\text { performance of } \\
\text { LEACH-1R is } \\
\text { better than } \\
\text { other clustering } \\
\text { protocols in } \\
\text { terms of } \\
\text { network } \\
\text { lifetime. }\end{array}$ \\
\hline \begin{tabular}{l}
\multicolumn{1}{c}{ Ningbo } \\
Wang; Ha \\
o \\
Zhu(2012)
\end{tabular} & \begin{tabular}{lr}
\multicolumn{1}{c}{ They } & have \\
added & energy \\
constraint & to \\
improve & the \\
lifetime of & of \\
wireless sensor \\
network and to \\
analyse the \\
performance of \\
leach protocol.
\end{tabular} & LEACH-R & \begin{tabular}{l}
\multicolumn{1}{c}{ Energy } \\
consumption \\
and lifetime is \\
improved by \\
using LEACH-R \\
protocol
\end{tabular} \\
\hline
\end{tabular}

\section{MethodologY}

The LEACH protocol suffers from the disadvantage that the remaining energy of every node has not been considered. Also, the time in which each node has to be selected as a $\mathrm{CH}$ is also not considered. [15][16] In case, if the low energy node has been considered as a $\mathrm{CH}$ then it decreases the lifetime of the network. To resolve this problem, Cuckoo search as an optimization algorithm has been used. CS helps to categorize the nodes on the basis of their energy consumption; these categories are then provided as an input to the SVM in order to train the system. Therefore, SVM classified the nodes and hence allocate data to that node which has higher energy or is a genuine node.

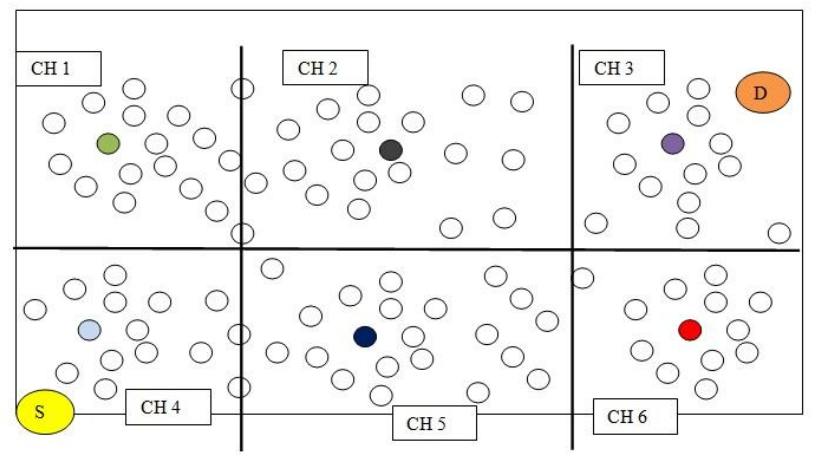

Fig 4: Dividing the entire network into different clusters

The entire network is divided into six different clusters namely $\mathrm{CH} 1, \mathrm{CH} 2, \mathrm{CH} 3, \mathrm{CH} 4, \mathrm{CH} 5$ and $\mathrm{CH} 6$ respectively. The $\mathrm{CH}$ using LEACH protocol has been selected that contains maximum energy and represented by different colours. The source node and the destination nodes are denoted by yellow and orange colours and are presented inthe $\mathrm{CH} 4$ and $\mathrm{CH} 3$ respectively.Source node createsa route using LEACH protocol by transmitting the data to its nearby $\mathrm{CH}$, the route formation is depicted in fig. 3 .

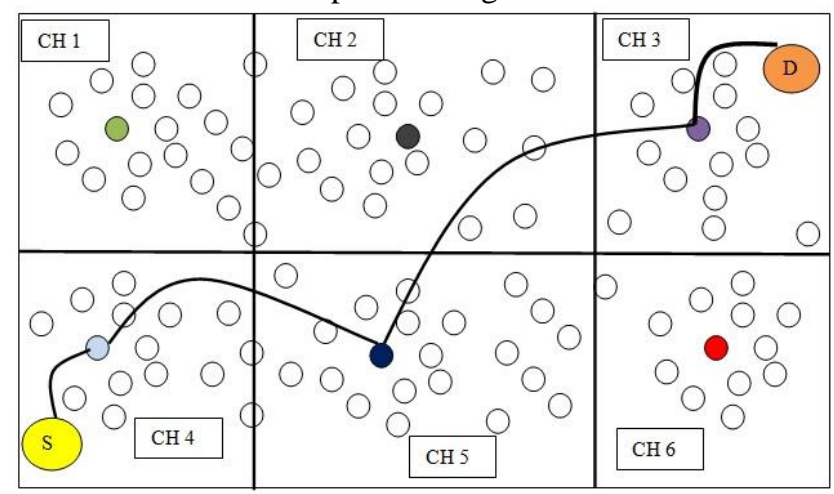

Fig 5: Route Formation using LEACH

Using LEACH protocol the data is transmitted between CH's, but the problem is like, it does not differentiate between genuine node or malicious node and also do not consider that the node has enough energy to behave like a $\mathrm{CH}$. To resolve this problem, CS as an optimization scheme has been used with a healthy function. On the basis of healthy function, the properties of the node are differentiated and a list is made that contains the node with higher energy and lower energy respectively.On the basis of these properties, SVM is trained and the trained architecture of SVM is shown in the fig. 5.

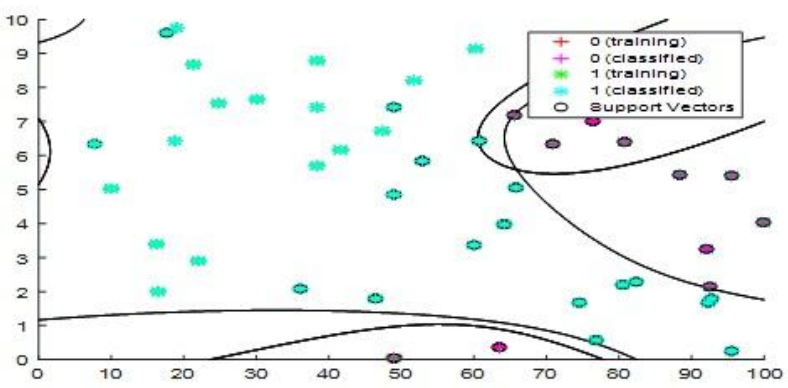

Fig 6: Trained SVM

SVM helps to select as appropriate $\mathrm{CH}$ that contains the highest energy within the cluster and hence increase the lifetime of the network.[18] At last, the performance of the network is computed, the results are discussed in the subsequent section.

\section{RESULT AND DISCUSSION}

The results are examined using MATLAB software, to determine the quality of the LEACH protocol in combination with CS and SVM. The results without CS and SVM and with $\mathrm{CS}+\mathrm{SVM}$ are compared. The graphical representation is shown in the following section. 


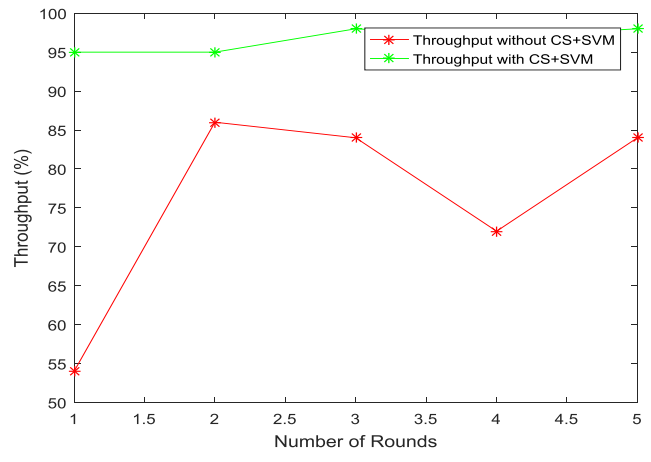

Figure 7: Throughput

The throughput represents the number of packets delivered to the destination node compared to the total packets transmitted from the source node. The green and the red line represent the throughput with (CS \& SVM) and without (CS \& SVM) respectively. From the fig.6, it is clear that in case of only LEACH protocol the throughput increased upto 2 iterations and then starts decreasing to 4 iterations and again increases from 4th to 5 the iterations. This is due to the improper selection of $\mathrm{CH}$. When CS and SVM have applied the node with higher energy has been considered and the throughput is increases for the entire cycle. The average value of throughput examined for the network with and without CS \&SVM are $76 \%$ and $96.6 \%$ respectively. Thus the enhancement in throughput of about $27.11 \%$ has been analyzed.

Table 4 Throughput

\begin{tabular}{|c|c|c|}
\hline $\begin{array}{c}\text { Number of } \\
\text { Rounds }\end{array}$ & $\begin{array}{c}\text { Without CS } \\
\text { +SVM }\end{array}$ & $\begin{array}{c}\text { With CS } \\
\text { +SVM }\end{array}$ \\
\hline 1 & 54 & 95 \\
\hline 2 & 86 & 95 \\
\hline 3 & 84 & 98 \\
\hline 4 & 72 & 97 \\
\hline 5 & 84 & 98 \\
\hline
\end{tabular}

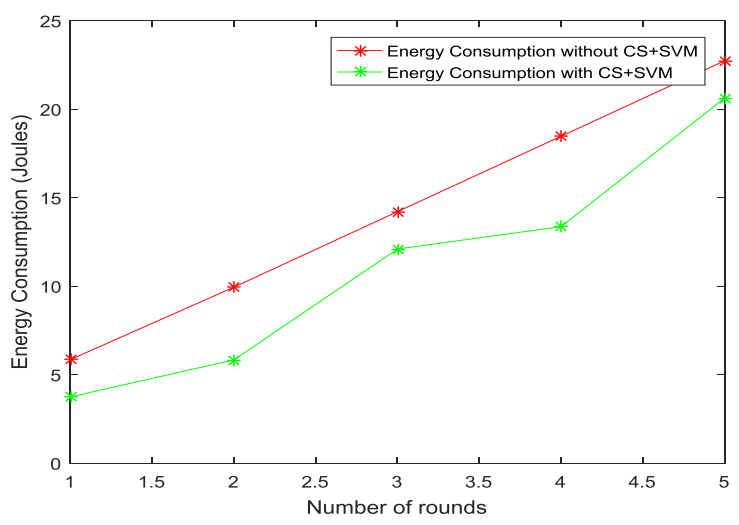

Figure 8: Energy Consumption

The energy consumed by the sensor nodes with LEACH protocol and when enhanced LEACH using (CS \&SVM) have been used is represented in fig. 7.It is seen that using CS \&SVM with LEACH protocol, the energy consumption is less compared to the energy consumption analyzed using LEACH protocol. The values examined are listed in table 2 .

Table 5: Energy Consumption (J)

\begin{tabular}{|c|c|c|}
\hline $\begin{array}{c}\text { Number of } \\
\text { Rounds }\end{array}$ & $\begin{array}{c}\text { Without CS } \\
\text { +SVM }\end{array}$ & $\begin{array}{c}\text { With CS } \\
\text { +SVM }\end{array}$ \\
\hline 1 & 5.8457 & 3.7376 \\
\hline 2 & 9.9387 & 5.8306 \\
\hline 3 & 14.2044 & 12.0963 \\
\hline 4 & 18.4640 & 13.3558 \\
\hline 5 & 22.7296 & 20.6215 \\
\hline
\end{tabular}

The average energy consumption examined with or without $\mathrm{CS}+\mathrm{SVM}$ technique are $14.23 \mathrm{~J}$ and $11.12 \mathrm{~J}$ respectively. Thus there is a reduction of $21.86 \%$ in the energy consumption has been observed.

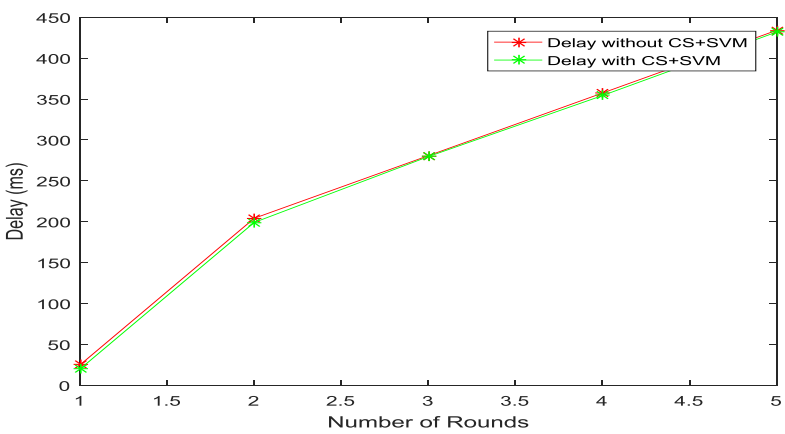

Figure 9: Delay

The delay rate represents the time gap in which the data is received at the receiver end. There is a very minor change exists in the delay value examined with CS \&SVM as well as without CS \& SVM. The values of delay are listed in table 3. Table 6: Delay (ms)

\begin{tabular}{|c|c|c|}
\hline $\begin{array}{c}\text { Number of } \\
\text { Rounds }\end{array}$ & $\begin{array}{c}\text { Without CS } \\
\text { +SVM }\end{array}$ & $\begin{array}{c}\text { With CS } \\
\text { +SVM }\end{array}$ \\
\hline 1 & 24.9555 & 19.8598 \\
\hline 2 & 204.2050 & 199.1092 \\
\hline 3 & 280.7406 & 279.6449 \\
\hline 4 & 357.3775 & 354.2817 \\
\hline 5 & 434.0617 & 431.9660 \\
\hline
\end{tabular}

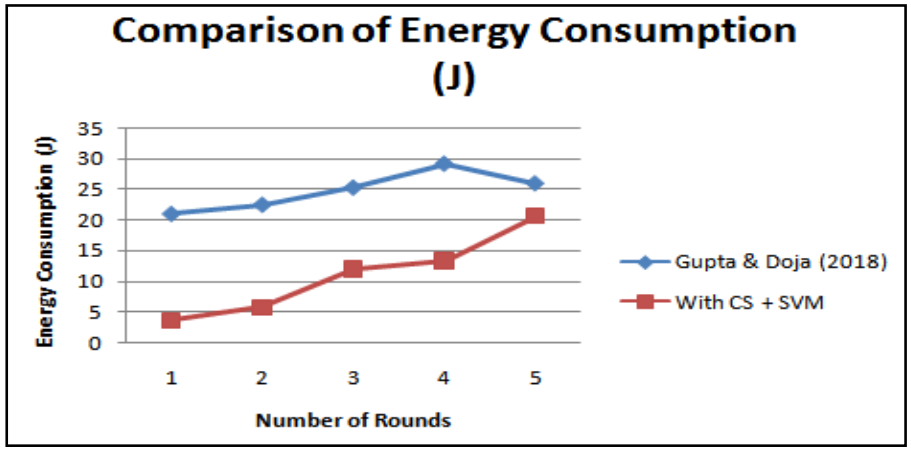

Figure 10 Comparison of proposed work withGupta \&Doja (2018)

The comparison of energy consumed by the nodes examined using CS \&SVM has been compared with the

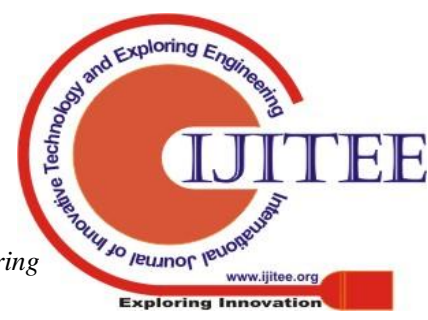


existing hybrid LEACH presented by Gupta \&Doja (214, 018 ). The average value examined for five numbers of rounds for proposed as well as for existing work is shown in fig. 9.

Table 7: Energy Consumption (J)

\begin{tabular}{|c|c|c|}
\hline $\begin{array}{l}\text { Number of } \\
\text { Rounds }\end{array}$ & $\begin{array}{c}\text { Gupta } \\
\text { \&Doja (2018) }\end{array}$ & $\begin{array}{l}\text { With CS } \\
\text { +SVM }\end{array}$ \\
\hline 1 & 21 & 3.7376 \\
\hline 2 & 22.5 & 5.8306 \\
\hline 3 & 25.3 & 12.0963 \\
\hline 4 & 29.2 & 13.3558 \\
\hline 5 & 26 & 20.6215 \\
\hline
\end{tabular}

Gupta \&Doja $(10,2018)$ have presented a hybrid LEACH protocol. This protocol selects $\mathrm{CH}$ dynamically by using the information related to the particular area as well as the node's co-ordinates location. The cluster formation has been done on the basis of this information. The network is divided into multiple zones and the $\mathrm{CH}$ has been performed in such a way so that the energy is balanced.[21]

The values examined for proposed and existing work are $11.12 \mathrm{~J}$ and $24.8 \mathrm{~J}$ respectively. Therefore, there is a reduction of $55.16 \%$ of the existing work. This is due to the proper selection of $\mathrm{CH}$ using optimization with a classification scheme.

\section{CONCLUSION}

From the experimental results discussed above, it is clear that by proper selection of $\mathrm{CH}$ using the concept of cuckoo search with SVM results into a minimization of energy consumption for the WSN. To show the efficiency of the proposed work, comparison between the LEACH protocol and when LEACH with CS and SVM is used in the network have been provided.[22] Using CS, the properties of nodes on the basis of their energy consumption rate has been classified and is used to train SVM.[24] Therefore, while creating a route, SVM matched the properties of the node with the stored properties and hence identify an appropriate and best $\mathrm{CH}$, which has higher energy and hence enhance the lifetime. From the comparison, it has been clear that the energy using CS with SVM upto $55.16 \%$ has been saved.[25]

\section{REFERENCES}

1. Zhang, W. H., Li, L. Y., ZHANG, L. M., \& WANG, X. Z. (2008). Energy consumption balance improvement of LEACH of WSN. Chinese Journal of Sensors and Actuators, 11, 1918-1922.

2. J. Wang, J. Cao, S. Ji, \& J. H. Park, "Energy-efficient cluster-based dynamic routes adjustment approach for wireless sensor networks with mobile sinks," The Journal of Supercomputing, Vol.73, no.7, 2017, pp.3277-3290.

3. A Bouyer, A. Hatamlou, \& M. Masdari, “ A new approach for decreasing energy in wireless sensor networks with hybrid LEACH protocol and fuzzy C-means algorithm," IJCNDS, Vol.14, No.4, pp. 2015 400-412.

4. C. Gherbi, Z. Aliouat, \& M. Benmohammed, An adaptive clustering approach to dynamic load balancing and energy efficiency in wireless sensor networks," Energy, Vol.114, 2016, pp. 647-662.

5. D. Jiang, Z. Xu, Li, W., \& Z. Chen, "Network coding-based energy-efficient multicast routing algorithm for multi-hop wireless networks," Journal of Systems and Software, Vol.104, 2015, pp.152-165. 6. S. K. Gupta, \& P. K. Jana, "Energy efficient clustering and routing algorithms for wireless sensor networks: GA based approach," Wireless Personal Communications, Vol. 83, No. 3, 2015., pp.2403-2423.
7. J. A. Khan, H. K. Qureshi, \& A. Iqbal, "Energy management in wireless sensor networks: A survey," Computers \& Electrical Engineering, Vol. 41, 2015, pp.159-176.

8. J. Kaur, S. Randhawa, \& S. Jain, "A novel energy efficient cluster head selection method for wireless sensor networks," Int. J. Wireless Microwave Technol, Vol. 8, No. 2, 2018., pp.37-51.

9. J. N. Al-Karaki, \& A. E. Kamal, "Routing techniques in wireless sensor networks: a survey," IEEE wireless communications, Vol. 11, No. 6, 2004, pp. 6-28.

10. Heinzelman, W. B., Chandrakasan, A. P., \&Balakrishnan, H. (2002). An application-specific protocol architecture for wireless microsensor networks. IEEE Transactions on wireless communications, 1(4), 660-670. 11. Muruganathan, S. D., Ma, D. C., Bhasin, R. I., \&Fapojuwo, A. O. (2005). A centralized energy-efficient routing protocol for wireless sensor networks. IEEE Communications Magazine, 43(3), S8-13.

12. Ghasemzadeh, H., Rezaeian, M., Touranposhti, F. D., \&Ghasemian, M. M. (2014, September). BN-LEACH: an improvement on LEACH protocol using Bayesian networks for energy consumption reduction in wireless sensor networks. In 7'th International Symposium on Telecommunications (IST'2014) (pp. 1138-1143). IEEE.

13. Wang, N., \& Zhu, H. (2012, March). An energy efficient algrithm based on leach protocol. In 2012 International Conference on Computer Science and Electronics Engineering (Vol. 2, pp. 339-342). IEEE.

14. Gupta, V., \&Doja, M. N. (2018). H-leach: Modified and efficient leach protocol for hybrid clustering scenario in wireless sensor networks. In Next-generation networks (pp. 399-408). Springer, Singapore.

15. Omari, M., \&Laroui, S. (2015). Simulation, comparison and analysis of Wireless Sensor Networks protocols: LEACH, LEACH-C, LEACH-1R, and HEED. 2015 4th International Conference on Electrical Engineering (ICEE).

16. Leach Protocol in Wireless Sensor network (2017) International Journal of Science and Research, 6(12), 808-813.

17. Ma, Z., \& Li, G. (2017).Improvement on LEACH-C Protocol for Wireless Sensor Network. Artificial Intelligence Science and Technology. 18. Katiyar, V., Chand, N., Gautam, G. C., \& Kumar, A. (2011). Improvement in LEACH protocol for large-scale wireless sensor networks. 2011 International Conference on Emerging Trends in Electrical and Computer Technology.

19. A Survey on LEACH Protocols in Wireless Sensor Networks. (2019). International Journal of Recent Trends in Engineering and Research,5(1), 20-23.

20. Improved Clustering Based Routing Protocol for Wireless Sensor Networks. (2016). International Journal of Science and Research (IJSR),5(2), 247-250.

21. Manjunatha, P., Verma, A. K., \&Srividya, A. (2010). Fuzzy Based Optimized Routing Protocol for Wireless Sensor Networks. Lecture Notes in gineeringAdvancesElectricalEn in Wireless Sensors and Sensor Networks, 273-282

22. Luo, Z., \&Jannett, T. C. (2012). A multi-objective method to balance energy consumption and performance for energy-based target localization in wireless sensor networks. 2012 Proceedings of IEEE Southeastcon.

23. Yan, F. (2011). Wireless sensor networks hierarchical routing algorithm based on nodes energy balance. 2011 International Conference on Electric Information and Control Engineering.

24. Pawar, S., \&Kasliwal, P. (2012). Design and Evaluation of En-LEACH Routing Protocol for Wireless Sensor Network. 2012 International Conference on Cyber-Enabled Distributed Computing and Knowledge Discovery.

25. Kai, L. (2009). A Mine-Environment-Based Energy-Efficient Routing Algorithm for Wireless Sensor Network. 2009 Ninth International Conference on Hybrid Intelligent Systems. 


\section{AUTHORS PROFILE}

Navjot Kaur, received my B.Tech degree in Computer Science and Engneering from CGC Landran,Mohali,Punjab in 2017.I am currently Pursuing M.tech in computer Science and engineering at Chandigarh Engneering College (CEC),Landran,Mohali,Punjab. Her Research Interest include computer networking.

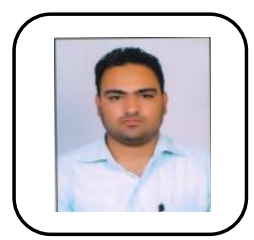

Mr.Rajeev Sharma, received his Bachelor's degree in Computer Science and Engneering from Desh Bhagat Engg. college , Mandi Gobindgarh, India.Mtech from Guru Nanak Dev Engg. college, Ludhaina, Punjab, India. Pursuing Phd from Chandigarh University .

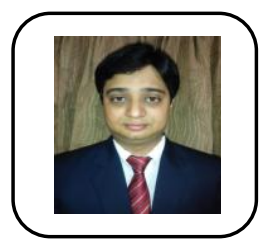

Dr.Manish Mahajan, done his Bachelor's degree in Informattion Technology from Kurukshetra University in 2004.He has Completed his M.tech and Ph.d in Computer Science Engneering from Punjab Technical University in 2010. Currently he is pursuing Ph.d in Computer Science Engneering from Punjab Technical University .His area of research is digital image processing, steganography,encryption and data security. He is having 15 years of experience in teaching and more than 8 years research experience.Currently he is working as HOD and Professor at Computer Science Engneering Department at Chandigarh Engneering College,Landran Mohali Punjab 